\title{
Prediction of Fabric porosity from Yarn Diameter and effect of different spinning techniques and process on porosity
}

\author{
Nusrat Bibi", M. Umar Abdullah Makhdoom** \\ * Department of Textile Design, University College of Art \& Design, Faculty of Arts, \\ The Islamia University of Bahawalpur, Pakistan \\ ** R\&D product development, Masood Textile Mills, Pakistan \\ DOI: 10.29322/IJSRP.11.06.2021.p11491 \\ http://dx.doi.org/10.29322/IJSRP.11.06.2021.p11491
}

\begin{abstract}
Along many other factors, fabric comfort depends upon the fabric cover factor and porosity. This research work is based on the prediction of fabric porosity by measuring diameters (by empirical formula) of different yarns and put them in an equation for porosity measurement. This will be helpful to predict the porosity of different fabric structures by knowing the yarn diameter only. Effect of different yarn diameters on porosity produced by various spinning techniques (ring, compact) and processes (carded, combed) is also the part of study. At the end, comparison between the relationships of yarn diameter, spinning process and techniques and fabric porosity is shown graphically. This research work is helpful regarding the comfort properties of fabric.
\end{abstract}

Index Terms- Prediction of Fabric, spinning techniques, process on porosity

\section{INTRODUCTION}

A ir permeability of a fabric depends on many factors, one of them is a fabric geometrical structure [1] and this property is known as porosity. Fabric cover factor and porosity are very important for the evaluation of moisture and air in between the yarns (inter yarn pores) and between the individual filaments of the yarns of the fabric (intrayarn pores) [2].The maximum vapor or moisture passes through the inter-yarn zone of fabric [3] However, the adsorption and absorption of any gas, liquid and solid materials into the fabric depend on intra-yarn porosity [4-5], weave type and its structure. Moreover, tightly woven fabrics resist the dye liquor more as compared to loosely woven fabrics. It is because when tightly woven fabrics composed of Hydrophilic yarns wet, swells the yarns, increase the compactness and act as a barrier for liquid to flow [6]. Therefore, much work has been done on the assessment of fabric porosity for accessing the liquor flow into the fabric. It was assessed by various Geometrical formulas [7-8], by image processing and analysis techniques.

The calculation of yarns diameter, ends and picks per $\mathrm{cm}$, and yarn spacing is laborious and time consuming job, depends on the operator efficiency. Work has been carried out to evaluate the fabric appearance [9], thread density, yarn density, weave pattern, fabric count, yarn skewness [10-11] and fabric cover factor [12-13] using Fourier transfer technique.

Fabric porosity depends generally on the fabric and yarns constructions. It was shown that for tightly woven fabrics there exists a good agreement between air permeability and inter fiber pore volume or porosity [14]. Correlation between air permeability and construction parameters of fabrics is not so strong for open weave fabrics [15]. Various techniques have been adopted for the calculation of fabric porosity i.e. considering cover factor, using yarn diameter, considering surface volume and so many. In this research paper fabric porosity is calculated by yarn diameter and fabric cover factor. [16]

Yarn diameter is used to predict fabric structural parameters such as width, cover factor, porosity, and fabric comfort and so on. Since thousands of ends or picks are presented side-by-side in the woven or the knit fabrics, a slight change in yarn diameter can result in a substantial change in the overall fabric cover factor. Measuring yarn diameter and compressibility and their effect on fabric quality is important to both the fabric designer and the textile technologist. In fact, the dimensional and mechanical characteristics of fabrics are dependent on yarn diameter, thread spacing of warp and weft in woven fabrics, courses and Wales per unit length and stitch length in knitted goods [17].

Many researchers studied the yarn diameter and they estimated it using empirical formula. One of the most commonly used expressions for estimating yarn diameter is developed by Peirce in 1937[18]. In a recent study, Elmoghazy et al in $1993^{[5]}$ developed empirical expressions for estimating the diameters of ring-spun, rotor-spun and MJS air-jet spun yarns.[19] 
ISSN 2250-3153

Different yarn diameters can be achieved using different spinning techniques and procedures; however there is no prominent effect of spinning techniques on yarn diameter. Yarn count plays a vital role for varying the yarn diameter i.e. for finer count yarn diameter will less and vice versa.

\section{MATERIALS AND METHODS:}

Two different types of yarn counts $\mathrm{Ne} 30 / \mathrm{s}$ and $\mathrm{Ne} 40 / \mathrm{s}$ with different TM levels ranging from 4.18 to 4.65 were used in this research study. These yarn samples were prepared using different spinning techniques (Ring \& Compact) and processes (carded \& combed) and total no of samples were 16. After preparing given yarn samples, checked the diameter of given yarn samples by Empirical formula. For calculating Yarn diameter, made lea of given samples on wrapping wheal. Weighted the given samples in grams and calculated the actual count then by using following formula measured yarn diameter of each. Formula for calculating the yarn diameter is given below.

$$
\begin{aligned}
\text { Yarn Diameter } & =\frac{\frac{1}{28 \sqrt{N e}} \text { (in inch) }}{28.4} \\
& =28 \sqrt{N e} \text { (in mm) }
\end{aligned}
$$

Detail of yarn count, spinning type, T.M value, weight, actual count and yarn diameter for prepared 16 yarn samples

\begin{tabular}{|c|c|c|c|c|c|c|c|c|c|c|}
\hline S. No. & Count & $\begin{array}{l}\text { Spinning } \\
\text { Type }\end{array}$ & TM & W1 (g) & W2 (g) & $\begin{array}{l}\text { Count } \\
1\end{array}$ & $\begin{array}{l}\text { Count } \\
2\end{array}$ & $\begin{array}{l}\text { Dia1 } \\
(\mathbf{m m})\end{array}$ & $\begin{array}{l}\text { Dia2 } \\
(\mathbf{m m})\end{array}$ & $\begin{array}{l}\text { Avg. } \\
\text { Diameter } \\
\text { (mm) }\end{array}$ \\
\hline 1 & 30 & CM/Ring & 4.48 & 2.09 & 2.08 & 31.00 & 31.15 & 0.163 & 0.163 & 0.163 \\
\hline 2 & 30 & CD/Ring & 4.65 & 2.07 & 2.08 & 31.30 & 31.15 & 0.162 & 0.163 & 0.162 \\
\hline 3 & 30 & CM/Comp & 4.11 & 2.07 & 2.1 & 31.30 & 30.86 & 0.162 & 0.163 & 0.163 \\
\hline 4 & 30 & CM/Ring & 4.65 & 2.11 & 2.12 & 30.71 & 30.57 & 0.164 & 0.164 & 0.164 \\
\hline 5 & 30 & CD/Comp & 4.3 & 2.15 & 2.12 & 30.14 & 30.57 & 0.165 & 0.164 & 0.165 \\
\hline 6 & 30 & CM/Comp & 4.3 & 2.11 & 2.15 & 30.71 & 30.14 & 0.164 & 0.165 & 0.164 \\
\hline 7 & 30 & CM/Comp & 4.11 & 2.13 & 2.12 & 30.42 & 30.57 & 0.164 & 0.164 & 0.164 \\
\hline 8 & 30 & CD/Ring & 4.48 & 2.12 & 2.08 & 30.57 & 31.15 & 0.164 & 0.163 & 0.163 \\
\hline \multicolumn{11}{|c|}{$\mathrm{Ne} 40 / \mathrm{s}$} \\
\hline 9 & 40 & CD/Ring & 4.45 & 1.58 & 1.55 & 41.01 & 41.81 & 0.142 & 0.140 & 0.141 \\
\hline 10 & 40 & CM/Ring & 4.45 & 1.59 & 1.53 & 40.75 & 42.35 & 0.142 & 0.139 & 0.141 \\
\hline 11 & 40 & CM/Comp & 4.18 & 1.58 & 1.55 & 41.01 & 41.81 & 0.142 & 0.140 & 0.141 \\
\hline 12 & 40 & CD/Ring & 4.65 & 1.56 & 1.58 & 41.54 & 41.01 & 0.141 & 0.142 & 0.141 \\
\hline 13 & 40 & CD/Comp & 4.28 & 1.58 & 1.58 & 41.01 & 41.01 & 0.142 & 0.142 & 0.142 \\
\hline 14 & 40 & CM/Comp & 4.28 & 1.56 & 1.61 & 41.54 & 40.25 & 0.141 & 0.143 & 0.142 \\
\hline 15 & 40 & CM/Ring & 4.65 & 1.53 & 1.58 & 42.35 & 41.01 & 0.139 & 0.142 & 0.141 \\
\hline 16 & 40 & CM/Comp & 4.18 & 1.58 & 1.55 & 41.01 & 41.81 & 0.142 & 0.140 & 0.141 \\
\hline
\end{tabular}
is shown in table 1.

Table 1: Detail of given yarn samples

After calculating the diameter of given yarn samples calculated the fabric porosity using cover factor and yarn diameter values. Fabric properties such as cover factor and porosity are very important for assessing the behavior of flow of dye Liquor in between the yarns (inter-yarn pores) and between the individual filaments of the yarns of the fabric (intra-yarn pores) [20]. However, the adsorption and absorption of any liquid, gas and solid materials into the fabric depend on the inter-yarn and intra-yarn porosity geometrical expression of calculating the inter-yarn porosity of the woven fabric is given in Equation (1).

Porosity $=\frac{p_{1} p_{2}}{(p 1+d 1)\left(p_{2}+d 2\right)}$

Where D1 is diameter of warp yarn, D2 is diameter of weft yarn, P1 is warp spacing, and P2 is weft spacing. 


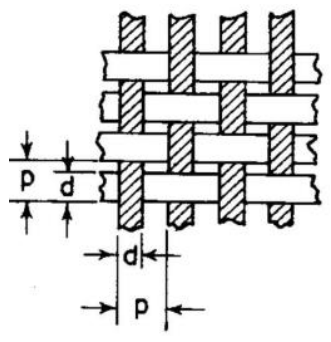

A

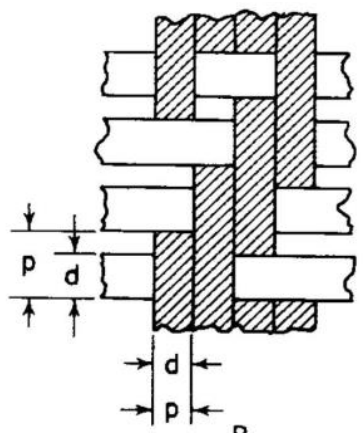

The above figure shows projected views of two woven cloths of different construction. At A the warp and the weft threads cover the area of the cloth only partially, but at B the cloth area is covered completely with no spaces left between the adjacent warp yarns, and it will be seen that the relative closeness of yarns in a woven cloth is dependent upon the ratio of yarn diameter, $d$, to yarn spacing, p. This ratio known as relative cover can be defined as the proportion of a projected view of a given area of cloth which is covered by threads.

For the prediction of porosity yarn diameter is already measured for each sample as shown in Table (1). The next step is to calculate the Warp and Weft spacing (P1, P2), for obtaining the P1 and P2, EPI and PPI are necessary. For calculation of P1 and P2 required data is given in above Table 2 .

\begin{tabular}{|l|l|}
\hline Ne 40/s \\
\hline Warp Count & 40 \\
\hline Weft Count & 40 \\
\hline EPI & 100 \\
\hline PPI & 78 \\
\hline Width & 110 \\
\hline Weave & $1 / 1$ plain \\
\hline Ne 30/s \\
\hline Warp Count & 30 \\
\hline Weft Count & 30 \\
\hline EPI & 91 \\
\hline PPI & 86 \\
\hline Width & 63 \\
\hline Weave & $1 / 1$ Plain \\
\hline
\end{tabular}

\section{Table 2: Data for Calculation of P1 and P2 Value}

By using data from Table 2, which shows fabric construction, EPI, PPI, fabric weave and fabric width, calculated the value of P1 and P2 by given formula and put them in Equation 1 and measure the porosity values at different factors and levels.

$\mathbf{D}=28 \sqrt{\mathrm{Ne}}$

$P 1=((25.4 / E P I)-d 1)$

P2 $=(25.4 /$ PPI $)-d 2) \ldots . . . . . . . . . . .(4)$

D1 and D2 are already measured, using Equation 3 and 4 measured the values of P1 and P2 and put them in equation 1 for porosity calculation. The calculated value of porosity for $\mathrm{Ne} 30 / \mathrm{s}$ and $\mathrm{Ne} 40 / \mathrm{s}$ is given below. 


\begin{tabular}{|c|c|c|c|c|}
\hline $\mathrm{p} 1$ & $\mathrm{p} 2$ & $\mathrm{~d} 1$ & $\mathrm{~d} 2$ & porosity \\
\hline 0.116 & 0.132 & 0.163 & 0.163 & 18.64 \\
\hline 0.117 & 0.132 & 0.162 & 0.163 & 18.87 \\
\hline 0.117 & 0.132 & 0.162 & 0.163 & 18.87 \\
\hline 0.115 & 0.131 & 0.164 & 0.164 & 18.34 \\
\hline 0.114 & 0.131 & 0.165 & 0.164 & 18.12 \\
\hline 0.115 & 0.130 & 0.164 & 0.165 & 18.26 \\
\hline 0.115 & 0.131 & 0.164 & 0.164 & 18.34 \\
\hline 0.115 & 0.132 & 0.164 & 0.163 & 18.42 \\
\hline
\end{tabular}

Table 3: Porosity calculation for $\mathrm{Ne} 30 / \mathrm{s}$

\begin{tabular}{|c|c|c|c|c|}
\hline $\mathrm{p} 1$ & $\mathrm{p} 2$ & $\mathrm{~d} 1$ & $\mathrm{~d} 2$ & porosity \\
\hline 0.137 & 0.155 & 0.142 & 0.14 & 25.67 \\
\hline 0.137 & 0.156 & 0.142 & 0.139 & 25.74 \\
\hline 0.137 & 0.155 & 0.142 & 0.14 & 25.67 \\
\hline 0.138 & 0.153 & 0.141 & 0.142 & 25.78 \\
\hline 0.137 & 0.153 & 0.142 & 0.142 & 25.51 \\
\hline 0.138 & 0.152 & 0.141 & 0.143 & 25.70 \\
\hline 0.140 & 0.153 & 0.139 & 0.142 & 26.33 \\
\hline 0.137 & 0.155 & 0.142 & 0.14 & 25.67 \\
\hline
\end{tabular}

Table 4: Porosity calculation for $\mathrm{Ne} 40 / \mathrm{s}$

\section{RESUlTS AND DisCUSSIONS:}

By checking Table 1, it is shown that there is no significant difference between diameter of yarn on the basis of spinning techniques, procedure and TM level, but it is significant in case of different counts. Diameter varies from count to count, for 30/s count its values are ranges from 0.162 0.165, while in case of 40/s values are ranges from $0.141 \sim 0.142$.

When we make a graph between yarn diameter and spinning techniques, keeping yarn count constant, it is shown that there is no significant difference in yarn diameter. However cdd compact yarn show highest diameter and cdd ring show lowest diameter. This behavior is clearly illustrated by Graph 1.

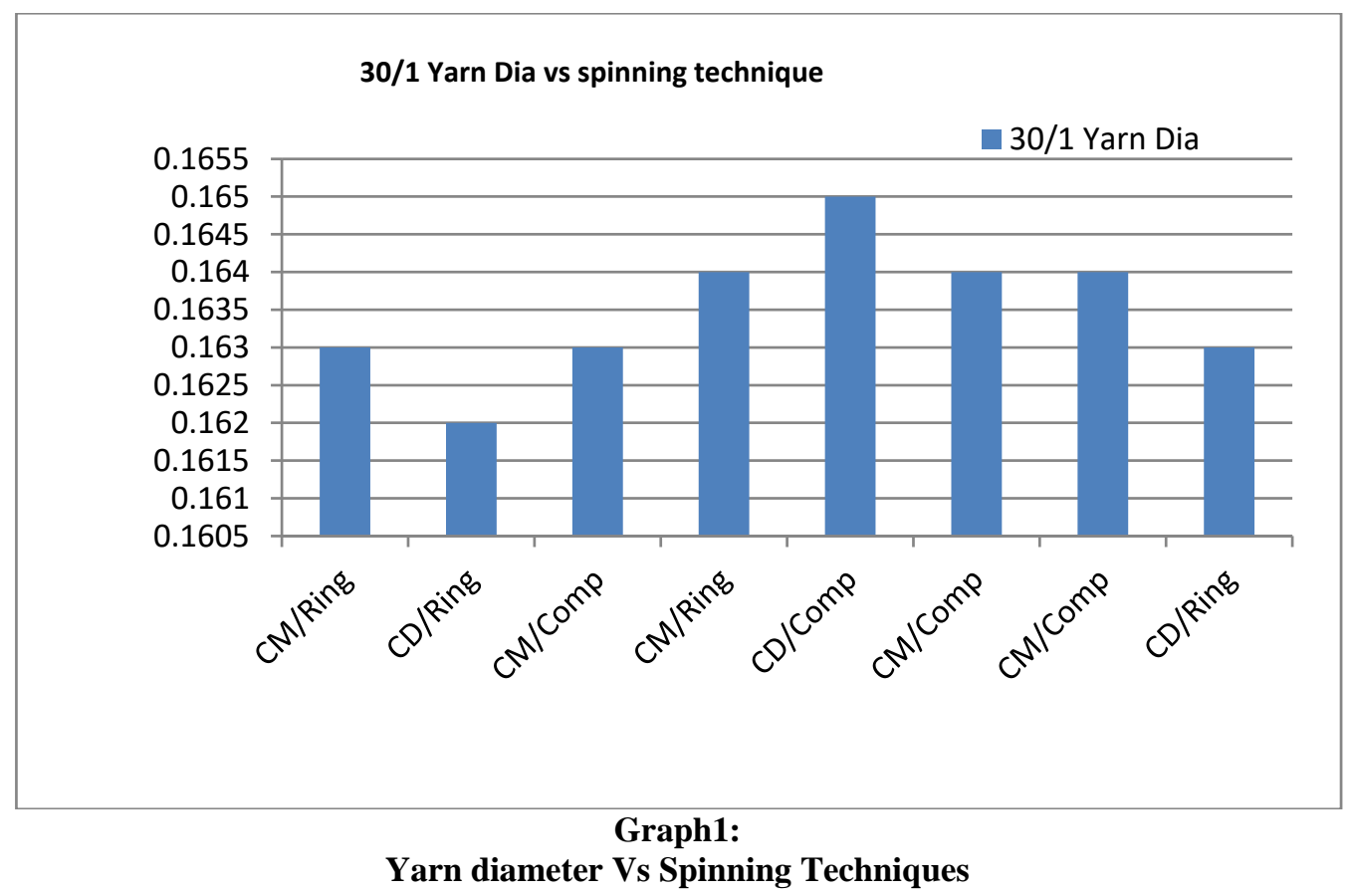




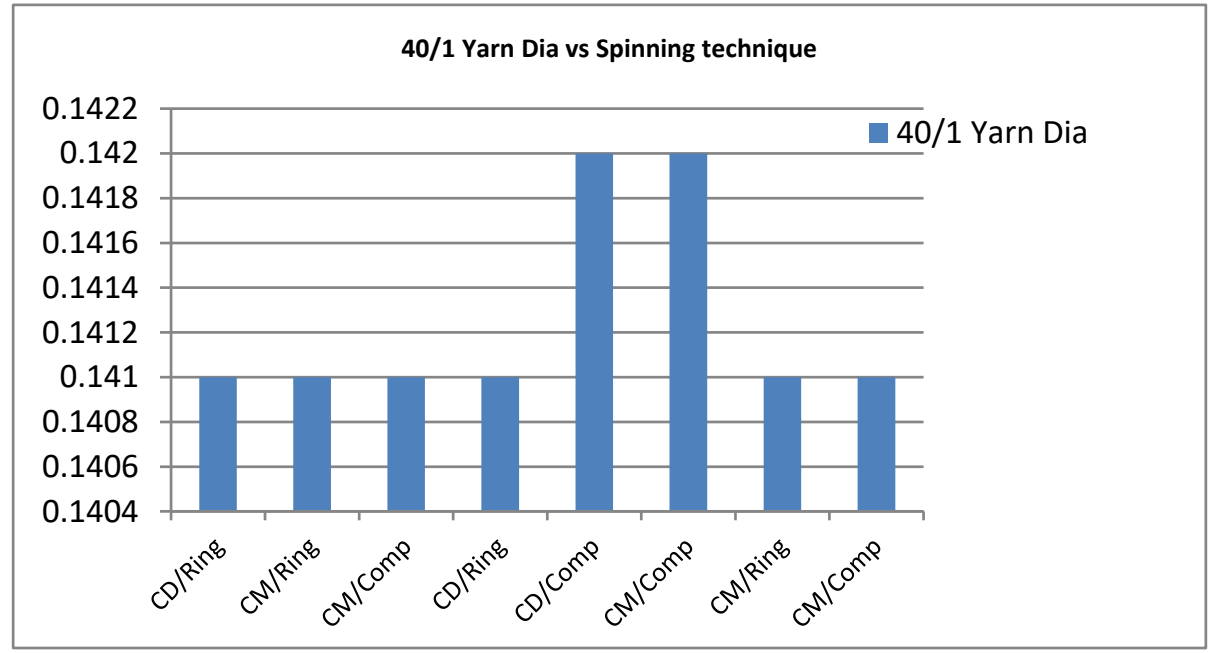

Graph 2: Yarn diameter Vs Spinning Techniques

Graph 2 shows the impact of Spinning technique and process on Ne40/s. It shows that when we use compact spinning either it is carded or combed, yarn diameter is on increasing side. Very small variation in diameter is shown; it means there is no significant effect of spinning techniques on yarn diameter.

Graph 3 describes the difference in diameter, when two different yarn counts i.e. Ne 30/s and 40/s are compared. When yarn count goes on finer side, yarn diameter decreases and vice versa. However Graph shows almost consistent behavior based on spinning techniques, while considering the $30 / \mathrm{s}$ and $40 / \mathrm{s}$ separately.

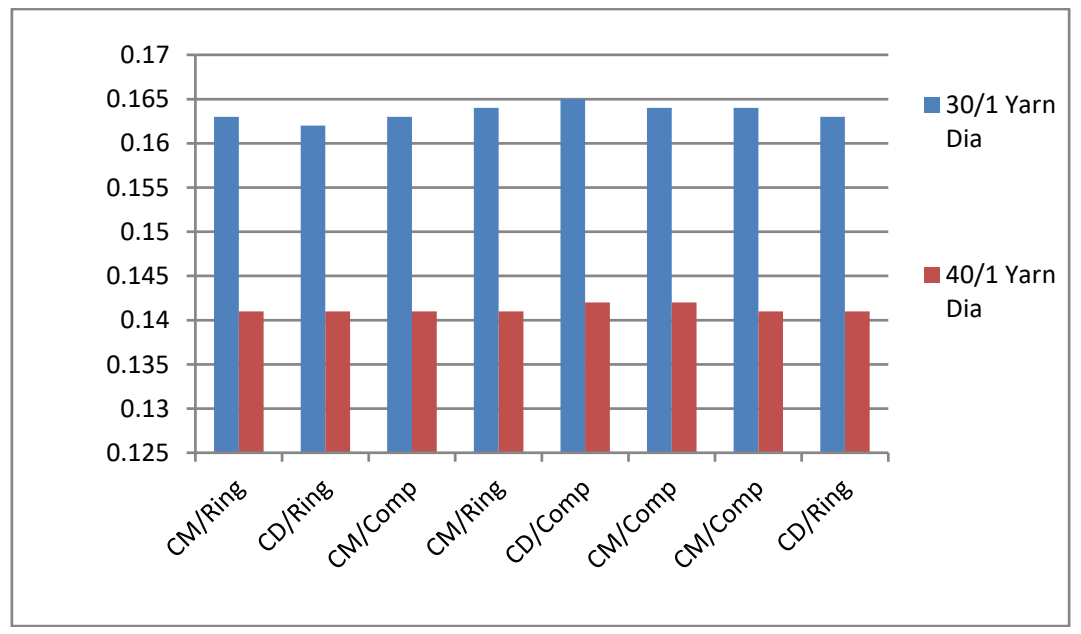

\section{Graph 3: Yarn diameter based on yarn counts}

Graph 4 shows the variation in porosity, based on spinning techniques and processes. For 30/s count porosity ranges are from 18.1 18.9. no significant effect found, all samples are showing same behavior. Ring (carded) and compact (combed) have high value of porosity, while compact (carded) has low value of porosity.

If we compare the Graph 1and graph 4 it shows that by increasing diameter of yarn porosity value will decrease and vice versa. Keen observation of graph tells us that when we use compact spinning and carded technique porosity value decreases, and diameter of yarn increases. It is concluded that by increasing diameter of yarn porosity value decreases. This behavior is easily shown in the case of carded compact sample by increasing diameter porosity value decreases. 


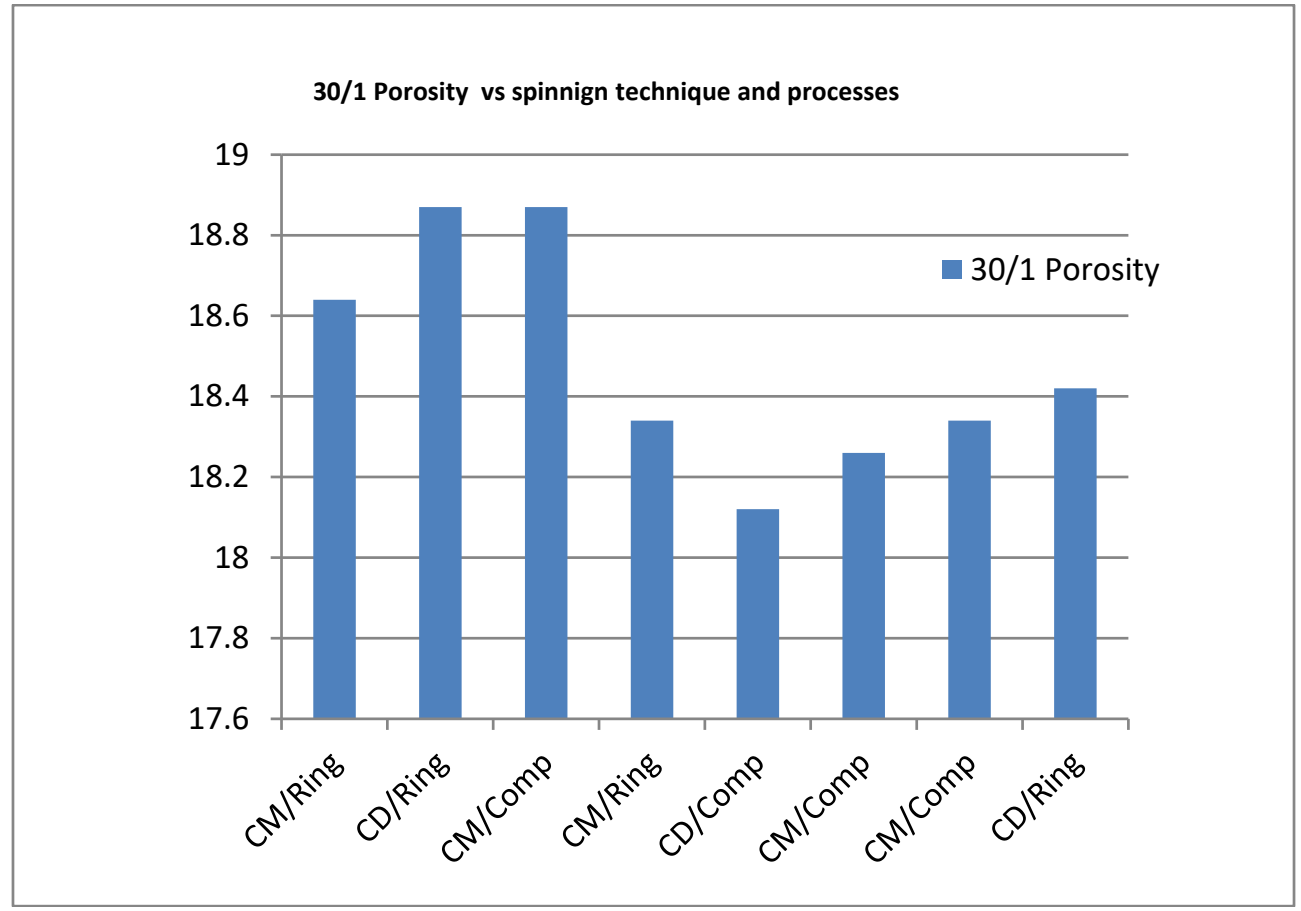

\section{Graph 4: Porosity Vs Spinning Techniques Ne30/s}

In case of Ne 40/s same results achieved like Ne 30/s i.e. by comparing Graph $2 \& 4$ diameter of combed compact sample is on higher side and its porosity value is on lower side. It shows the significance that whenever yarn diameter increases at the same time porosity value decreases and vice versa.

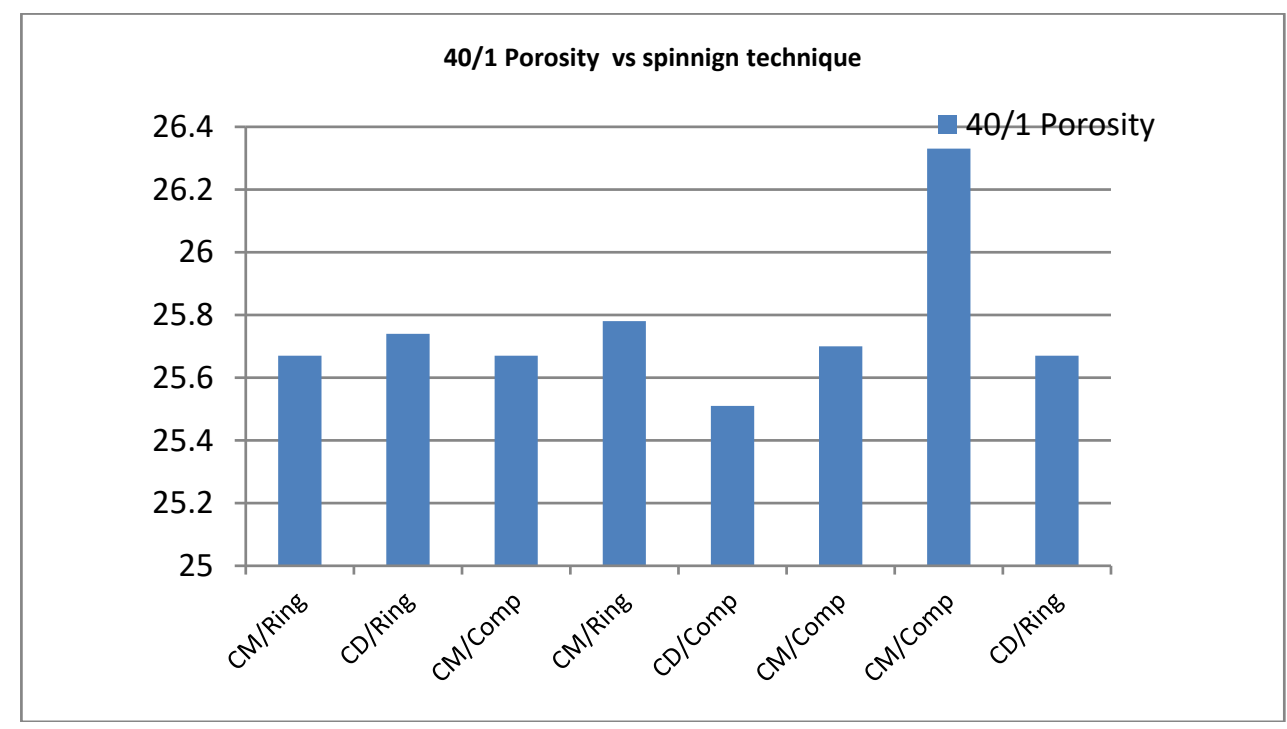

Graph 5: Porosity vs Spinning Techniques 40/s 


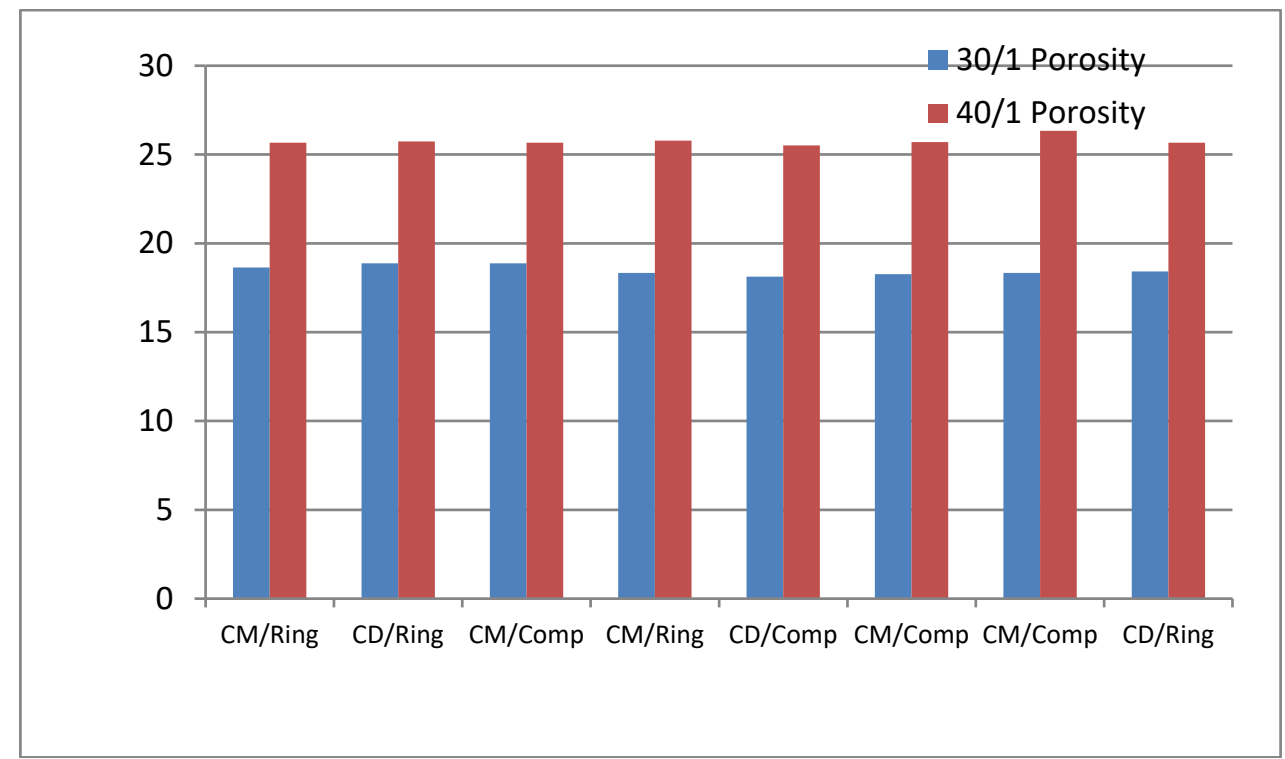

Graph 6: porosity based on yarn counts

If we observe the abovegraph, which is a comparison of porosity values of $\mathrm{Ne} 30 / \mathrm{s}$ and 40/s, it comes to know that $\mathrm{Ne} 30 / \mathrm{s}$ has less porosity value ranges from (15 20$) \%$ then 40/s which has the values ranges from (25 28)\%. The reason is that Ne 30/s has more diameter then $\mathrm{Ne} 40 / \mathrm{s}$, ultimately results in decrease in velocity. Which is clearly shown from the graph.

\section{CONCLUSION:}

Some findings of this research work are given below.

It is concluded that by using yarn Diameter and spacing between the end, porosity is easily measure by the given formula Porosity $p_{1} p_{2}$

$=\overline{(p 1+d 1)(p 2+d 2)}$.

No significant effect of spinning technique and procedure, on yarn diameter as well as fabric porosity is found.

Variation in Yarn count (finer, coarser) has greater impact on yarn diameter and fabric porosity. With increases in yarn diameter fabric porosity is decreased and vice versa.

Yarn diameter calculated for 30/s is ranges from $0.162 \sim 0.165$ while for $40 / \mathrm{s}$ it is $0.141 \sim 0.142$, while porosity values are (20 25)\% for 30/s and (25 28)\% for $\mathrm{Ne} 40 / \mathrm{s}$.

When yarn count goes on finer side, yarn diameter decreases and vice versa.

Variation due to spinning techniques and procedure is discussed above in results and discussion section.

\section{REFERENCES}

[1] J. Militký M. Trávníčková V. Bajzík, "Air Permeability and Light Transmission of Weaves", Vlákna a textil vol 5, No3, 125 -134, 1998.

[2] McGregor, R., "The Effect of Rate of Flow on Rate of Dyeing II: The Mechanism of Fluid Flow through Textiles and Its Significance in Dyeing", Journal of Society of Dyers and Colorist, Volume 18, No. 10, pp. 429-438,

[3] Research Journal, Volume 60, No. 7, pp. 427-428, 1990.

[4] Volume Porosity and Permeability inDouble Layer Woven Fabrics", AUTEX Research Journal,Volume 5, 2005

[5] "Permeability and Textiles", Textiles, Volume 4, No. 1, pp. 19-23, 1975

[6] "Elementary of Cloth Structure",Woven Cloth Construction, Manchester, Burtterworth\& Co and The Textile Institute, 1967.

[7] The Geometry of Cloth Structure", Journalof Textile Institute, Volume 28, No. 3, pp. 45-97, 1937.

[8] Fabric Dimensions and Properties",Principal of Textile Testing, Fabric, Third Edition, London, Boston, Sydney, Wellington, Durban, Toronto,Butterworths, 1968.

[9] Ravandi, S.A.H., and Toriumi, K., "Fourier-Transform Analysis of Plain Weave Fabrics Appearance", Textile Research Journal, Volume 65, No. 11, pp. 676-683, 1995.

[10] "Identifying Fabric Structures with Fast FourierTransform Techniques", Textile Research Journal,Volume 66, No. 8, pp. 496-506, 1996.

[11] "Determination of Weave Type in Woven Fabric byDigital Image Processing", Journal of Textile MachinerySociety of Japan, Volume 35, No. 2, pp. 1-4, 1989.

[12] “Automatic Structure Analysis andObjective Evaluation of Woven Fabric Using Image Analysis”, Textile Research Journal, Volume 71, No. 3,pp. $261-270,2001$.

[13] "Objective Measure of Woven Fabric'sCover Factor by Image Processing”, Textile ResearchJournal, Volume 80, No. 1, pp. 35-44, 2009.

[14] “Woven Fabric Analysis by Image Processing Part-I: Identification ofWeave Patterns”, Textile Research Journal, Volume 70, No. 6, pp. 48-485, 2000.

[15] On the Use of Image Processing Techniques for the Estimation of the Porosity of TextileFabrics", Proceedings of World Academy of Science,Engineering and Technology, Volume 2, Ardil, C., Editor,World Academic Science, Engineering \& Tech-Waset,Canakkale,pp.73-76,2005. 
[16] Mechanics of Woven Fabrics, Part III: Critical Review of Weavability Limit Studies, Textile Research Journal, Volume 63 (7), pp 371-378, 1993.

[17] Understanding the Fibre-to-yarn System: Yarn Characteristics, 1993, pp 89-116.

[18] The Geometry of Cloth Structure, Journal of Textile Institute1937,28T45.

[19] Understanding the Fibre-to-yarn System: Yarn Characteristics, 1993, pp 89-116.

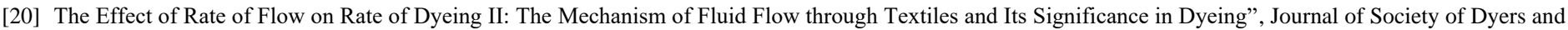
Colorist, Volume 18, No. 10, pp. 429-438,1965.

\section{AUTHORS}

First Author - Nusrat Bibi (Assistant Professor), Department of Textile Design, University College of Art \& Design, Faculty of Arts, The Islamia University of Bahawalpur, Pakistan, Mail Id: nusratbibi1987@ gmail.com, Cell\# 03008667684

Second Author - M. Umar Abdullah Makhdum, R\&D product development, Masood Textile Mills, Pakistan, Mail Id: umar.makhdoom@masoodtextile.com, Cell\# 03000702974 